\title{
Crise organizacional e sensemaking: o caso de um hospital público no contexto da pandemia de influenza A (H1N1)
}

\author{
Organizational crisis and sensemaking: the case of a public hospital within the context of \\ the influenza $A(\mathrm{H} 1 \mathrm{~N} 1)$ pandemic
}

\author{
André Davi Eberle ${ }^{1}$ \\ Adriana Machado Casali ${ }^{2}$
}

\begin{abstract}
Resumo
Esta pesquisa é um estudo de caso no qual se analisou uma situação de crise organizacional ocorrida em um hospital público de grande porte no contexto da pandemia de influenza A (H1N1) de 2009. O objetivo da pesquisa foi analisar o processo de crise organizacional, considerando os processos de sensemaking realizados pelos funcionários do hospital durante a crise. O referencial teórico foi construído com base nas temáticas da crise organizacional e do processo de sensemaking. Realizou-se a coleta de dados por meio de entrevistas individuais semiestruturadas, grupos focais e análise documental. Os dados foram submetidos à técnica de análise de conteúdo. A análise do processo de crise organizacional ocorrido no hospital foi realizada a partir da caracterização dos seguintes períodos: (I) o período anterior à ruptura da crise, no qual se verificou a ocorrência de sinais de alerta e de vulnerabilidade; (II) o momento de ruptura, relacionado à ocorrência do evento desencadeador da crise; (III) a fase aguda da crise. Os resultados da pesquisa indicaram que os processos de sensemaking realizados pelos funcionários exerceram influência no modo como eles agiram na crise organizacional.
\end{abstract}

Palavras-chave: Crise organizacional. Sensemaking. Pandemia de influenza A (H1N1).

\begin{abstract}
This research is a case study in which an organizational crisis that occurred in a large public hospital within the context of the influenza $A(\mathrm{H} 1 \mathrm{~N} 1)$ pandemic of 2009 was analyzed. This research aimed to analyze the process of organizational crisis, taking into account the sensemaking processes carried out by hospital professionals during the crisis. The theoretical framework was constructed with the themes of organizational crisis and sensemaking as a basis. Data collection was achieved through semi-structured individual interviews, focus groups, and documentary analysis. Content analysis was then carried out. The analysis of the organizational crisis process which occurred in the hospital was performed according to the characterization of the following periods: $(\mathrm{I})$ the period prior to the crisis disruption, when warning and vulnerability signs were observed; (II) the disruptive moment, related to the occurrence of the event triggering the crisis; (III) the acute crisis phase. Our results indicated that the sensemaking processes performed by professionals influence how they acted during the organizational crisis.
\end{abstract}

Keywords: Organizational crisis. Sensemaking. Influenza A (H1N1) pandemic.

Artigo submetido em 24 de janeiro de 2012 e aceito para publicação em 10 de outubro de 2012.

${ }^{1}$ Mestre em administração e psicólogo pela Universidade Federal do Paraná; Professor do Centro Universitário Uninter; Pesquisador e profissional autônomo na área de psicologia do trabalho. Endereço: Rua Nicolau Scheffer, 22, Boa Vista, CEP 82640-390, Curitiba PR, Brasil. E-mail andre-psicologia@hotmail.com

Doutora em engenharia da produção pela Universidade Federal de Santa Catarina; Professora adjunta licenciada da Universidade Federal do Paraná. Endereço: Trav. Cap. Clementino Paraná, 130 ap. 141B, Água Verde, CEP 80620-180, Curitiba - PR, Brasil. Email adrianamcasali@gmail.com 


\section{Introdução}

O termo "crise" é empregado em diversos campos, dentre os quais podem ser citados a Sociologia, a História, a Ciência Política, a Economia e a Psicologia. Na área da Administração, o termo é considerado a partir da constatação de que as organizações são suscetíveis à ocorrência de crises, havendo uma preocupação quanto aos impactos e danos causados, bem como quanto às ações de prevenção e de gestão de crises organizacionais (FINK, 1986; PAUCHANT e DOUVILLE, 1993; KOVOOR-MISRA, 1995; PEARSON e CLAIR, 1998).

Considerando apenas os últimos anos, é possível identificar diversas situações de crise que foram amplamente divulgadas na mídia, por exemplo: a crise do apagão aéreo em 2006 e 2007, acompanhada por dois dos maiores acidentes da aviação civil nacional, a colisão entre o Boeing da Gol e o jato Legacy, em 2006, e o acidente do voo TAM 3054, em 2007, no aeroporto de Congonhas, em São Paulo; a queda do avião da Air France que partiu do Rio de Janeiro com destino a Paris em maio de 2009; a crise econômica internacional de 2008 e 2009; o recall de milhões de veículos da Toyota em todo o mundo em 2010; o vazamento de petróleo no Golfo do México, decorrente da explosão de uma plataforma da British Petroleum no segundo trimestre de 2010; o acidente nuclear de Fukushima, decorrente do terremoto e do tsunami que atingiram o Japão em março de 2011, dentre outras.

Como demonstrado em alguns desses exemplos, as crises que ocorrem nas organizações podem ser desencadeadas por vários fatores e eventos: problemas de ordem financeira e econômica, processos de aquisição e fusão, necessidade de recall de produtos, mudanças tecnológicas, políticas e culturais, podendo, ainda, estar relacionados à ocorrência de acidentes industriais e desastres tecnológicos ou naturais (SHRIVASTAVA, MITROFF, MILLER et al., 1988; PERROW, 1999; KOVOOR-MISRA, CLAIR e BETTENHAUSEN, 2001).

As pesquisas sobre crises organizacionais podem enfocar a análise de diversos aspectos, tais como: financeiros, tecnológicos, políticos, sociais, psicológicos, culturais; além disso, podem estar relacionados à estratégia, à comunicação, às relações públicas e à gestão de crises (PAUCHANT e DOUVILLE, 1993; KOVOOR-MISRA, 1995; PEARSON e CLAIR, 1998; KOVOOR-MISRA, CLAIR e BETTENHAUSEN, 2001).

Este trabalho teve por objetivo analisar o processo de crise organizacional ocorrido em um hospital público de grande porte, localizado na cidade de Curitiba-PR, no contexto da pandemia de influenza A (H1N1) de 2009. Até o final daquele ano havia casos confirmados de infecções por influenza A (H1N1) em mais de 200 países, inclusive no Brasil, sendo que a Região Sul do país foi a que registrou as maiores taxas de incidência de casos e de mortalidade (MINISTÉRIO DA SAÚDE, 2010). Esse hospital, aqui denominado Hospital X, foi definido como o hospital de referência de Curitiba e sua região metropolitana para o atendimento dos pacientes com influenza A (H1N1). Houve um impacto significativo na dinâmica de funcionamento do hospital, principalmente em decorrência da grande demanda de internamento de pacientes com influenza A (H1N1) em estado grave.

Priorizou-se o enfoque de aspectos psicológicos e sociais da crise organizacional, considerados a partir da análise dos processos de sensemaking (construção de sentidos) realizados pelos funcionários do hospital ao longo do processo de crise (WEICK, 1988; 1993; 1995; 2010; PAUCHANT e DOUVILLE, 1993; PEARSON e CLAIR, 1998). Trata-se de uma reflexão sobre como essas pessoas construíram sentidos plausíveis para as experiências que vivenciaram no hospital durante a crise.

Este trabalho está organizado do seguinte modo: inicialmente, apresenta-se o referencial teórico, seguido da descrição dos procedimentos metodológicos; posteriormente, os dados serão apresentados e analisados; e, por fim, serão tecidas as considerações finais. 


\section{Referencial Teórico}

Esta seção está estruturada a partir das duas categorias de análise deste estudo: crises organizacionais e processos de sensemaking.

\section{Crises organizacionais}

Os primeiros estudos sobre crise, na área da Administração, foram realizados no início da década de 1960, sendo observado um número significativo de publicações a partir de meados da década de 1980 (PAUCHANT e DOUVILLE, 1993). Essas pesquisas focalizaram, principalmente, a análise de catástrofes e acidentes industriais de grandes proporções, tais como os casos de Bhopal, Chernobyl, Challenger e Exxon Valdez (TURNER, 1976; PERROW, 1999; PEARSON, ROUX-DUFORT e CLAIR, 2007; HUTCHINS e WANG, 2008).

A realização de pesquisas sobre crise organizacional e gestão de crise no contexto brasileiro é recente, encontra-se em fase inicial de desenvolvimento, havendo poucos estudos e publicações que possuam como foco principal a compreensão das crises organizacionais e sua gestão (SANTANA, 1998; 2000; SALINAS, 2001; GALINDO e NOGUEIRA, 2008). No Brasil, a temática da gestão de crises começou a ser abordada principalmente por atores das áreas de Relações Públicas e Comunicação Organizacional (SALINAS, 2001; GALINDO e NOGUEIRA, 2008), com foco na questão da comunicação de riscos (ALVES, 2007; BATISTA, 2007) e no papel das relações públicas na gestão das crises (OLIVEIRA, 2007).

Há uma ampla variedade de conceitos e perspectivas de análise no campo de pesquisa em crises organizacionais. Mesmo não contemplando toda essa amplitude, apresentam-se a seguir alguns desses conceitos e perspectivas.

Uma crise organizacional pode ser definida como "um evento de baixa probabilidade e alto impacto que ameaça a viabilidade da organização e é caracterizado pela ambiguidade de causa, efeito e meios de resolução, bem como pela crença de que as decisões precisam ser tomadas rapidamente" (PEARSON e CLAIR, 1998, p. 60, tradução nossa). A ambiguidade de causas, efeitos e meios de resolução é uma característica relevante da crise organizacional, remetendo ao esforço realizado pelos atores organizacionais para construir sentidos plausíveis sobre o que está acontecendo na situação de crise (WEICK, 1988; 1993).

As características de alto impacto e de necessidade de urgência na tomada de decisões também são enfatizadas no conceito de crise organizacional proposto por Pauchant e Douville (1993, p. 45-46, tradução nossa):

São situações destruidoras que afetam uma organização ou determinado sistema como um todo e desafiam pressupostos básicos anteriormente sustentados; frequentemente elas requerem decisões e ações urgentes e originais, conduzindo potencialmente a uma posterior reestruturação tanto do sistema afetado como dos pressupostos básicos feitos pelos membros do sistema.

A partir desses dois conceitos é possível definir alguns elementos que são considerados neste estudo essenciais para a caracterização de uma crise organizacional: que seja uma situação (I) que cause alto impacto na organização, ameaçando em algum grau sua viabilidade; (II) com um elevado grau de ambiguidade; (III) que provoque o questionamento de pressupostos anteriormente sustentados na organização; e (IV) que gere a necessidade de ações e decisões com caráter de urgência.

Segundo Pearson e Clair (1998), as crises organizacionais podem ser analisadas a partir de três perspectivas principais: psicológica, social-política e tecnológico-estrutural. 
As pesquisas realizadas sob a perspectiva psicológica se utilizam de teorias cognitivas e psicanalíticas, bem como de estudos psicológicos sobre o trauma, para enfatizar que os indivíduos ocupam um papel importante nas crises organizacionais. Contudo, Pearson e Clair (1998) observam que poucas pesquisas têm abordado a questão da experiência de trauma psicológico nas vítimas de crises organizacionais, geralmente funcionários da organização que tiveram algum dano físico e/ou psicológico, e pessoas ligadas aos membros da organização.

$\mathrm{Na}$ perspectiva social-política, as pesquisas enfatizam aspectos da crise relacionados a colapsos dos significados compartilhados entre membros da organização e dos processos de legitimação e institucionalização das relações sociais. Pearson e Clair (1998, p. 64, tradução nossa) afirmam que, nessa perspectiva, "todas as crises possuem em comum o colapso da construção social da realidade". Portanto, considera-se que diante de uma crise organizacional pode ocorrer uma perda de significados, crenças e valores compartilhados até então na organização (PEARSON e CLAIR, 1998).

Na perspectiva tecnológico-estrutural, as pesquisas enfatizam como o desenvolvimento tecnológico, além de oferecer avanços na produção, contribui para a potencial ocorrência de grandes destruições. Um estudo fundamental nessa perspectiva é o realizado por Perrow (1999), no qual o autor destaca como o alto potencial para ocorrência de crises é uma característica inerente às tecnologias de alto risco, como, por exemplo, plantas de energia nuclear e indústrias químicas.

Assim, de acordo com essa classificação de perspectivas propostas por Pearson e Clair (1998), considera-se que nesta pesquisa a crise organizacional foi analisada com base em aspectos tanto da perspectiva psicológica quanto da perspectiva social-política.

Segundo Pearson, Roux-Dufort e Clair (2007), como a grande maioria das pesquisas sobre crise organizacional foi realizada a partir da análise de acidentes industriais e desastres naturais, ocorreu uma acentuação do caráter de excepcionalidade das crises. Para os autores, a gestão de crise se tornou uma ciência do excepcional ao focalizar prioritariamente a ocorrência de eventos raros, ao invés de analisar os processos pelo qual a normalidade se torna anormal. Nesse sentido, Roux-Dufort (2007b, p. 107, tradução nossa) considera que "a natureza excepcional de algumas crises deixa a impressão de uma mudança abrupta de uma situação normal para uma situação de crise. As crises são, então, definidas como súbitas, inesperadas, surpreendentes e imprevisíveis". Roux-Dufort (2007b) reconhece que essas são características importantes da crise, porém, propõe que seja dada mais atenção à análise dos processos de transição entre a normalidade e a crise em sua fase aguda. Trata-se de uma mudança na forma de conceber e visualizar a crise, passando de uma visão da crise como um evento para um processo. Considerando que esta pesquisa foi realizada visando à compreensão da crise organizacional como um processo, cabe tecer algumas considerações sobre essa abordagem.

Primeiramente, é importante ressaltar que a noção de "evento desencadeador" da crise ainda permanece relevante na abordagem processual, principalmente porque esse evento é considerado o ponto de referência para a identificação da crise, ou seja, é ele que torna a crise visível (ROUX-DUFORT, 2007a; 2007b). Assim, segundo Roux-Dufort (2007a; 2009), nessa abordagem a crise é considerada um processo no qual uma das fases, a mais crítica, dá-se na ocorrência de uma ruptura gerada pelo evento desencadeador. Para Roux-Dufort (2007a, p. 228, tradução nossa):

A abordagem processual da crise proporciona outra perspectiva que nos conduz a ver o evento desencadeador como um fator que revela uma preexistente dinâmica da crise. Em outras palavras, o que a abordagem centrada no evento considera como crise (ou seja, o evento desencadeador), a abordagem processual vê apenas como o amplificador de um processo que começou muito antes.

Como sugerido pelo autor, um aspecto essencial da abordagem processual da crise organizacional é o olhar para os momentos e contextos que antecedem o evento desencadeador e a fase aguda da crise. Nesse sentido, 
há o entendimento de que existe um período de incubação que antecede o evento desencadeador da crise (TURNER, 1976; ROUX-DUFORT, 2007a; 2009). Segundo Turner (1976), esse período de incubação é caracterizado por uma corrente de eventos discrepantes que se desenvolvem e se acumulam sem que sejam percebidos ou compreendidos pelos atores envolvidos.

Ao propor uma perspectiva baseada na compreensão processual das crises organizacionais, Roux-Dufort (2007a, p. 228, tradução nossa) afirma que "as crises devem ser definidas por três dimensões: um processo de acumulação de imperfeições, um processo de acumulação de ignorância gerencial, e um evento desencadeador". Assim, a compreensão processual da crise organizacional se dá com base em dois processos que ocorrem nas organizações e que favorecem o desenvolvimento da crise: primeiro, o acúmulo gradual e a incubação de imperfeições organizacionais e, segundo, o desenvolvimento de um estado de ignorância que mantém os gestores "cegos" quanto à ocorrência dessas imperfeições (ROUX-DUFORT, 2009). RouxDufort (2009, p. 5, tradução nossa) afirma que "a ideia central é demonstrar que se permite que as imperfeições organizacionais cresçam e se tornem vulnerabilidades porque elas não são notadas ou levadas em consideração".

As imperfeições organizacionais são definidas como "anomalias, erros, discrepâncias, negligências, deficiências e lacunas (buracos) produzidos pela organização" (ROUX-DUFORT, 2007a, p. 229, tradução nossa). Essa definição está de acordo com a proposição do autor de que as organizações são entidades imperfeitas que produzem um fluxo contínuo de disfunções. Roux-Dufort (2007a; 2009) propõe que as imperfeições organizacionais sejam agrupadas em quatro categorias conforme uma distinção de graus hipotéticos de imperfeição. São elas: anomalias, vulnerabilidades, rupturas e crises. Um dos critérios para essa distinção refere-se ao nível de visibilidade dessas imperfeições diante dos gestores, as anomalias sendo menos visíveis que as vulnerabilidades e estas, por sua vez, menos visíveis que as rupturas e crises (ROUXDUFORT, 2007a; 2009).

As anomalias são entendidas como imperfeições organizacionais que causam ameaças imediatas à organização ou parte dela. Podem ser consideradas atos de negligência e erros muitas vezes tidos como normais e aceitáveis no andamento dos processos organizacionais (ROUX-DUFORT, 2007a). As vulnerabilidades já são um segundo estágio do desenvolvimento das imperfeições organizacionais, sendo produzidas pelo acúmulo e combinação de anomalias organizacionais que não foram gerenciadas ou que foram gerenciadas de modo inadequado (ROUX-DUFORT, 2007a). As rupturas ocorrem quando as vulnerabilidades atingem um nível de saturação. Segundo Roux-Dufort (2007a, p. 232, tradução nossa) a "ruptura está relacionada à noção de falha final e evento desencadeador". Segundo Roux-Dufort (2007a), essas rupturas caracterizam-se como eventos inesperados, provenientes tanto de dentro da organização como de fora, que subitamente precipitam a organização para uma crise. As crises, por fim, são o último grau das imperfeições organizacionais e revelam uma série de falhas internas latentes na organização. Roux-Dufort (2007a) descreve que uma característica dessa situação de crise é a de que os eventos ocorridos transpassam os muros da organização, chamando a atenção da mídia e fazendo com que as vulnerabilidades internas da organização se tornem visíveis para os stakeholders externos (ROUX-DUFORT, 2007a; 2009).

É importante ressaltar que, ainda que esta pesquisa tenha adotado como base essa perspectiva processual conforme as proposições de Roux-Dufort (2007a; 2007b; 2009), não se pretende desenvolver, aqui, um raciocínio que estabeleça uma relação direta de causalidade entre as imperfeições organizacionais do Hospital X com a ruptura dessa crise. Ou seja, tendo em vista que este estudo analisa uma crise relacionada à ocorrência de uma pandemia de influenza, não se considerou que a crise seja resultante de um acúmulo de imperfeições organizacionais do Hospital X, mas, sim, de um conjunto complexo de fatores, muitos deles externos à organização e relacionados ao próprio desenvolvimento da pandemia. Portanto, nesse caso, não foram enfatizadas na análise as imperfeições organizacionais, mas, antes, os sinais de alerta e vulnerabilidade presentes no período antecedente à ruptura da crise (FINK, 1986; KOVOOR-MISRA, 1995; ROUXDUFORT, 2007a; 2007b). 


\section{Sensemaking}

O sensemaking é compreendido como um processo de construção de sentidos plausíveis para as experiências e situações vivenciadas pelas pessoas (WEICK, 1995; WEICK, SUTCLIFFE e OBSTFELD, 2005). Essa construção de sentidos (sensemaking) é um processo contínuo, social, retrospectivo e baseado na plausibilidade (WEICK, 1995).

No sensemaking ocorrem processos de percepção, categorização e rotulação de determinados sinais "extraídos" de um fluxo de experiências (WEICK, 1995; 2006; WEICK, SUTCLIFFE e OBSTFELD, 2005). Assim, o sensemaking também se constitui enquanto um mecanismo útil na criação de ordem dentro de um fluxo de experiências e informações (WEICK, 1995; 2006). As pessoas se envolvem continuamente em diversas circunstâncias e situações das quais extraem sinais que servem como base para a construção de sentidos. Weick (1995) afirma que as situações humanas vão sendo progressivamente esclarecidas através dos processos de sensemaking. Cria-se, por meio da construção de sentidos, uma relativa ordem para esse fluxo contínuo de circunstâncias e experiências vivenciadas (WEICK, SUTCLIFFE e OBSTFELD, 2005).

Weick (1995) ressalta que o sensemaking é diferente da interpretação, usualmente utilizada como sinônimo dele. Segundo o autor, "a distinção-chave é que o sensemaking é sobre o modo como as pessoas geram o que elas interpretam" (WEICK, 1995, p. 13, tradução nossa). O processo de sensemaking é mais abrangente do que o de interpretação; ele também leva em consideração a questão da escolha ou criação dos sinais que serão interpretados pelos sujeitos, ou seja, trata-se de um questionamento sobre como sinais específicos se destacam dos demais em um fluxo contínuo de experiências para, então, ser interpretados (WEICK, 1995). Portanto, Weick (1995, p. 13, tradução nossa) afirma que o "conceito de sensemaking enfatiza a ação, a atividade e a criação que estabelecem os traços que são interpretados e reinterpretados". As pessoas envolvidas no processo de sensemaking têm um papel ativo na criação dos sinais para os quais construirão sentidos plausíveis (WEICK, 1995; WEICK, SUTCLIFFE e OBSTFELD, 2005).

Weick (1995) considera que o sensemaking é um processo que pode ser compreendido a partir de sete características denominadas propriedades do sensemaking; são elas: (1) baseado na construção da identidade; (2) retrospectivo; (3) criado em ambientes sensatos; (4) social; (5) contínuo; (6) focado em e por sinais extraídos; e (7) guiado pela plausibilidade em vez da precisão. Tendo em vista a relevância de cada propriedade para a compreensão do sensemaking, apresentam-se os principais aspectos de cada uma, conforme o proposto por Weick (1995).

O processo de sensemaking é baseado na construção da identidade do sujeito que cria os sentidos. Apesar da tendência, a ênfase não deve ser dada apenas ao indivíduo como "o" criador de sentido, já que também se trata de um processo social, no qual a própria construção da identidade do sujeito se dá por meio das relações sociais (WEICK, 1995). O aspecto central, aqui, é que o processo de sensemaking é constituído conforme a identidade das pessoas envolvidas. Essa propriedade é essencial para a construção de sentidos porque o modo como as pessoas vivenciam as situações e experiências do dia a dia está intimamente relacionado à identidade delas, a como elas se enxergam e se definem em determinados contextos sociais.

O processo de sensemaking é retrospectivo. Essa característica do sensemaking remete ao fato de que a construção de sentido se dá com base naquilo que já foi vivenciado. Para Weick (1995, p. 25, tradução nossa), "a criação do significado é um processo de atenção, mas é uma atenção ao que já ocorreu". Determinada ação, por exemplo, só pode se tornar objeto de atenção depois de ter sido realizada.

O sensemaking é criado na ação. Weick afirma que utiliza o termo enactment, que pode ser traduzido como "criação na ação", porque preserva a ideia de que "o ator humano não reage ao ambiente, mas cria o ambiente" (WEICK, 1973, p. 64, grifo do autor), ou seja, as "pessoas frequentemente produzem parte do ambiente que enfrentam" (WEICK, 1995, p. 30, tradução nossa). Para Weick (1995) as pessoas criam seus ambientes e estes restringem e interferem em suas ações. 
Outra propriedade do sensemaking é que se trata de um processo social. Para Weick (1995) a interação social é mediada pela fala, por discursos e conversas, sendo estes focos importantes na análise do processo de construção de sentido. O sensemaking deve ser apreendido em um contexto social, que oferece o suporte e a validação de determinados sentidos. O sensemaking é definido como uma atividade social (WEICK, 1995).

O sensemaking é um processo contínuo, está sempre em movimento. Segundo Weick (1995, p. 43, tradução nossa) "compreender o sensemaking é ser sensível aos modos pelos quais as pessoas recortam momentos de fluxos contínuos e deles extraem sinais". Assim, o sensemaking possui essa característica porque a própria experiência é entendida como um fluxo contínuo (WEICK, 2001). O autor afirma que "falar sobre o sensemaking é falar sobre a realidade como uma realização contínua que toma forma quando as pessoas retrospectivamente constroem um sentido para as situações” (WEICK, 1995, p. 15, tradução nossa).

Em sua sexta propriedade, o sensemaking é um processo focado em sinais extraídos. A compreensão do sensemaking está relacionada ao modo como as pessoas selecionam os sinais do ambiente que serão alvo de interpretação, ou seja, os sentidos construídos estão diretamente relacionados aos sinais que foram selecionados pelos indivíduos (WEICK, 1995). Um elemento-chave para a compreensão dessa propriedade do sensemaking é o contexto no qual ele ocorre. A influência do contexto no processo de construção de sentidos ocorre de dois modos: primeiro, o contexto afeta o entendimento sobre o que é considerado um sinal digno de atenção; segundo, o contexto no qual se realiza o sensemaking interfere no modo como os sinais extraídos serão interpretados (WEICK, 1995).

Por fim, o sensemaking é dirigido mais pela plausibilidade do que pela precisão. Para Weick (1995), o critério da precisão é tido como secundário no processo de sensemaking - não é essencial. As percepções das pessoas sobre o ambiente não são sempre precisas. Aliás, segundo Weick (1995), diante da enorme variedade de sinais que podem ser extraídos e da multiplicidade de significados que podem ser atribuídos a eles, a exigência de precisão soa como uma intenção questionável. Ao invés da precisão, é mais importante que se construa uma história que preserve a plausibilidade e a coerência, que seja razoável e que capture tanto pensamentos quanto emoções. Weick (2001) afirma que construir um sentido é responder à seguinte pergunta: "Qual é a história aqui?". Assim, o sensemaking é sobre relatos que possuam credibilidade, que sejam socialmente aceitos e plausíveis em determinado contexto (WEICK, 1995; WEICK, SUTCLIFFE e OBSTFELD, 2005).

Segundo Weick (1995), essas sete propriedades do sensemaking devem ser entendidas como interrelacionadas. Em determinados momentos ou situações, pode ser que algumas dessas propriedades exerçam mais influência e sejam mais facilmente percebidas no processo de construção dos sentidos.

\section{Procedimentos Metodológicos}

Este estudo se caracteriza como uma pesquisa qualitativa (GODOY, 1995; DENZIN e LINCOLN, 1998). A estratégia de pesquisa adotada foi a de estudo de caso (YIN, 2005; STAKE, 2005; GODOY, 2006).

Segundo Yin (2005), um aspecto fundamental no estudo de caso é a utilização de fontes múltiplas de evidências, principalmente com o intuito de que seja realizada a triangulação de dados (YIN, 2005; STAKE, 2005). Portando, os dados foram coletados utilizando as seguintes técnicas: análise documental, entrevista semiestruturada e grupo focal (YIN, 2005; GODOY, 2006; FREITAS e OLIVEIRA, 2006).

$\mathrm{Na}$ análise documental foram considerados os seguintes documentos: planejamento estratégico do Hospital X; relatório de atividades do hospital referente ao ano de 2009; site institucional; boletins epidemiológicos de 2009 emitidos pela Organização Mundial da Saúde (OMS), pelo Ministério da Saúde, pela Secretaria Estadual da Saúde do Paraná e pela Secretaria Municipal de Saúde de Curitiba; informativos internos do Hospital X emitidos durante a pandemia; jornal interno e matérias publicadas em jornais de circulação estadual que abordaram temas referentes à pandemia de influenza $\mathrm{A}(\mathrm{H} 1 \mathrm{~N} 1)$. 
Foram realizadas quinze entrevistas durante o período de 22 de setembro a 10 de dezembro de 2010. A duração das entrevistas variou entre 30 minutos e 1 hora e 20 minutos. Os participantes da pesquisa foram selecionados por conveniência, seguindo o método "bola de neve" (BABBIE, 1998), no qual cada entrevistado sugeriu o nome de outros possíveis participantes. Foram entrevistados profissionais da saúde (médicos e enfermeiros), funcionários da área administrativa e gestores (gerentes de setor e diretores de unidades) das seguintes áreas do hospital: Direção Geral, Direção de Assistência, Direção Administrativa, Assessoria de Marketing Institucional, Unidade de Urgência e Emergência, Unidade de Terapia Intensiva, Infectologia, Epidemiologia, Comissão de Controle de Infecção Hospitalar, Unidade de Abastecimento, Anatomia Patológica e Qualidade/Acreditação Hospitalar.

Além das entrevistas, foram realizados dois grupos focais. O grupo focal 1 (GF 1) foi realizado com quatro funcionários do setor de Epidemiologia. $\mathrm{O}$ grupo focal 2 (GF 2) foi realizado com quatro funcionários do Comitê de Gripe do Hospital X, constituído no período da pandemia, sendo que esses participantes já haviam sido entrevistados individualmente antes da realização do grupo focal.

A análise dos dados foi realizada com base na metodologia da análise de conteúdo categorial temática (BARDIN, 2004). A definição dos temas ocorreu do seguinte modo: após a transcrição das entrevistas e dos grupos focais, realizou-se uma leitura atenta dos textos, sinalizando as temáticas abordadas em diferentes fragmentos do material. Na sequência, os relatos que abordavam temáticas em comum, isto é, que possuíam núcleos de sentido semelhantes, foram agrupados sob um mesmo tema (BARDIN, 2004). Adotou-se o critério de exclusividade (BARDIN, 2004), sendo que cada relato só foi considerado em relação a um único tema. Esses temas consolidados se constituíram como os elementos centrais dos resultados da pesquisa, apresentados a seguir.

\section{Resultados e Análise}

Os resultados apresentados nesta seção caracterizam o processo de crise organizacional ocorrido no Hospital $\mathrm{X}$ durante a pandemia de influenza A (H1N1) em 2009, bem como o processo de sensemaking realizado pelos funcionários em relação à crise. A Figura 1 representa o processo de crise, analisado em três períodos, denominados A, B e C, e o processo de sensemaking.

\section{Figura 1}

Processo de crise organizacional e sensemaking.

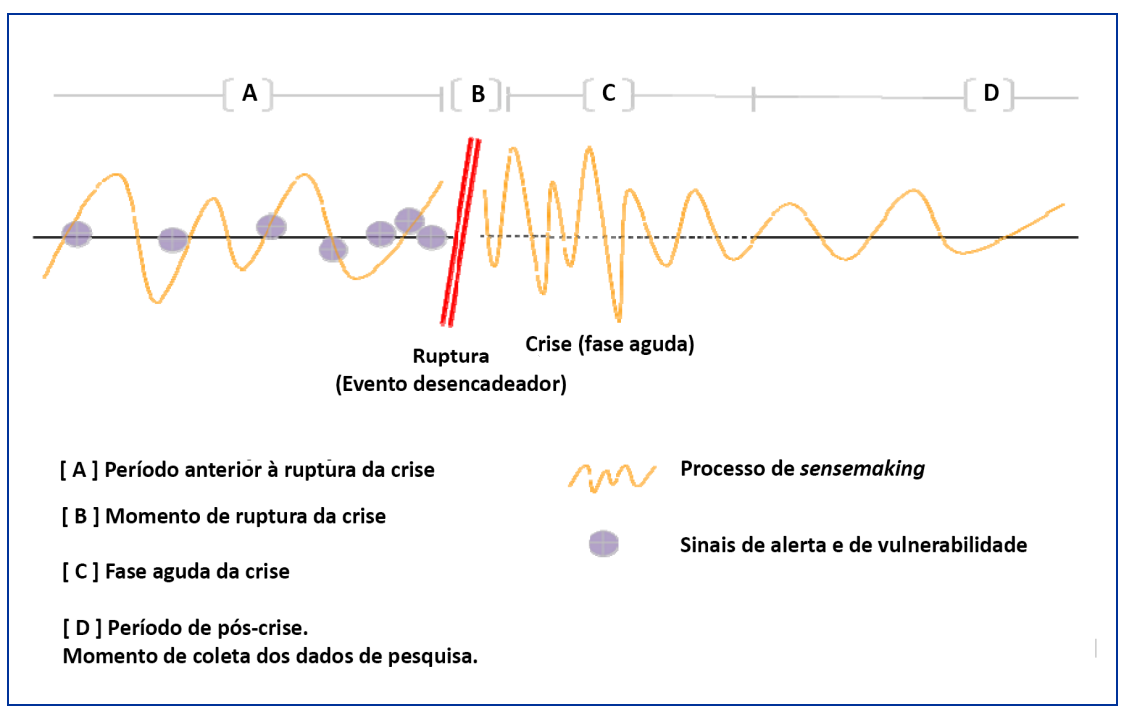

Fonte: Elaborada pelos autores. 
Os resultados deste trabalho são apresentados a partir de temas que sintetizam os dados referentes a cada um desses períodos do processo de crise. A análise do período A considerou os temas referentes ao período anterior à ruptura da crise, caracterizado pela ocorrência de sinais de alerta e de vulnerabilidade (FINK, 1986; KOVOOR-MISRA, 1995; KOVOOR-MISRA, CLAIR e BETTENHAUSEN, 2001; ROUXDUFORT, 2007a; 2007b; 2009). Na análise do momento B foram considerados os dados relacionados ao evento desencadeador e ao momento de ruptura da crise (TURNER, 1976; KOVOOR-MISRA, 1995; ROUX-DUFORT, 2007a; 2007b; 2009). No período C foram analisados os temas referentes à crise em si, ou seja, em sua fase aguda (FINK, 1986; ROUX-DUFORT, 2007a; 2007b; 2009).

\section{Tema 1 (período A): "O momento é de alerta e de vigilância total [...]"}

A análise dos dados apontou que no período anterior à fase aguda da crise ocorreram duas epidemias significativas: a severe acute respiratory syndrome (SARS) e a gripe aviária. Esses eventos foram considerados sinais de alerta (FINK, 1986; KOVOOR-MISRA, 1995) sobre a possível ocorrência de novas epidemias ou pandemias de influenza, como observado no relato a seguir:

Tivemos, assim, duas situações prévias onde a gente já teve uma mínima noção do que isso poderia ser uma foi a SARS, síndrome respiratória grave, e a influenza aviária, e mesmo naquela época a [E 10] já vinha sempre com esses alertas, e isso, assim, é uma coisa que a gente já sabia que uma hora ou outra ia acontecer, isso já vem se falando mundialmente há muito tempo [...] (E 1).

A Entrevistada 1 sinaliza que essas epidemias serviram como referência diante da nova gripe. Além de ser doenças respiratórias graves, a SARS e a gripe aviária assemelham-se à influenza A (HINl) porque na época de seu surgimento também foram tidas como possíveis pandemias. Segundo Thorson e Ekdahl (2005), a epidemia de influenza aviária na Ásia, a partir de 2003, serviu como um lembrete para a comunidade de saúde pública sobre a vulnerabilidade do mundo diante de epidemias emergentes. A SARS também foi preocupante para o sistema de saúde pública porque nas áreas afetadas a taxa de mortalidade chegou a aproximadamente 15\%, sendo que mais de $80 \%$ das infecções ocorreram em hospitais (WU, YANG e WU, 2004). Essas considerações, principalmente em relação ao impacto da SARS no sistema de saúde, também podem ser observadas no relato do grupo focal 2, apresentado a seguir:

- Nesse período da SARS [...] eles viram a importância da organização dos hospitais [...], era o corona vírus, outro vírus, conseguiram bloquear, mas ele nos serviu muito porque o corona vírus foi de alta transmissibilidade intra-hospitalar, com um adoecimento de perto de $20 \%$ dos profissionais de saúde, e serviu pra dar toda essa orientação e esse alerta.

- Sensibilizar as pessoas, né, que o problema tá aí e que pode acontecer (GF 2).

Apesar de não ter sido classificadas pela OMS como pandemias, a SARS e a gripe aviária serviram de sinais de alerta quanto à necessidade de realizar ações de preparação e organização dos hospitais diante da possibilidade de novas epidemias, sendo, portanto, eventos antecedentes importantes do processo de crise no Hospital X no contexto da pandemia de influenza A (H1N1).

Outros sinais de alerta verificados na pesquisa foram os avisos de uma profissional do Hospital X, como observado no seguinte relato: 
Quando eu voltei desse trabalho [sobre a preparação de estabelecimentos de saúde diante de casos inusitados de infecção respiratória aguda grave], eu fiz para a OPAS [Organização Pan-Americana da Saúde], nós fizemos várias reuniões, fizemos reunião em 2008 com a CCIH [Comissão de Controle de Infecção Hospitalar], fizemos duas reuniões com a Clínica Médica, levando esse alerta para os médicos do hospital, eu insistia muito na coleta de material virológico pra esses pacientes jovens, então, eles já estavam, vamos dizer, sensibilizados pro pega, né, o pessoal falava, "nossa, olha a boca da [E 10]”, que eu já vinha falando das coisas [...] (E 10).

Os alertas dados pela Entrevistada 10 aos profissionais do Hospital X, ainda em 2008, também foram considerados sinais de alerta significativos do período anterior à crise. Após a confirmação da pandemia de influenza A (H1N1) em 2009, a contundência desses alertas foram reconhecidos por outros profissionais do hospital, como expresso na fala "nossa, olha a boca da [E 10]".

Os comunicados oficiais da OMS, do Ministério da Saúde, da Secretaria Estadual de Saúde do Paraná, da Secretaria Municipal da Saúde de Curitiba e do próprio Hospital X, divulgados em abril de 2009, sobre a notificação de casos de um novo tipo de influenza, também foram considerados sinais de alerta do processo de crise.

O primeiro alerta foi o comunicado emitido pela OMS em 24 de abril de 2009, informando que

[...] o governo dos Estados Unidos relatou sete casos confirmados em humanos de influenza suína A (H1N1) [...]. O número de casos vem aumentando continuamente em abril, sendo que em 23 de abril havia mais de 854 casos de pneumonia na capital [...] (OMS, 2009, p. 1).

Após esse informe, foram emitidos outros comunicados oficiais do Ministério da Saúde, da Secretaria Estadual da Saúde do Paraná e da Secretaria Municipal de Saúde de Curitiba. Os primeiros casos de influenza A (H1N1) no México e nos Estados Unidos também foram noticiados pela imprensa nos meios de comunicação de massa. Um dos entrevistados relatou que tomou conhecimento da nova influenza por uma notícia na televisão:

Então, quando a coisa começou, foi no dia 27 de abril, 26 de abril, no domingo à noite, saiu essa história no Fantástico, que tinham surgido os primeiros casos no México e tal, e foi interessante porque na segunda-feira, oito horas da manhã, tava todo mundo já lá na Epidemiologia, nós do Controle de infecção, Infectologia Adulto, Infectologia Pediátrica, a [E 10], todo mundo com o mesmo alerta, e agora? (E 1).

Verificou-se que no dia 27 de abril de 2009, três dias após o comunicado da OMS, ocorreu a primeira reunião sobre o assunto entre profissionais de diferentes setores do Hospital X. Tal ação indica que esse comunicado já foi reconhecido por alguns membros do hospital como um possível sinal de vulnerabilidade, sobretudo pela preocupação que demonstraram em relação ao que fazer diante do alerta inicial. A partir dessa reunião foram realizadas ações para a divulgação do alerta e para a adoção de medidas de controle de infecção no hospital, mesmo que ainda que não houvesse casos suspeitos no Brasil. Ainda no dia 27 de abril de 2009 foi divulgado um comunicado no Hospital X com a seguinte mensagem:

O momento é de alerta e de vigilância total para a detecção oportuna dos primeiros casos e notificação imediata, tomada imediata das medidas de controle de infecção (utilização de máscara cirúrgica para atenção da triagem e no atendimento dos casos suspeitos) e coleta de amostra viral o mais rápido possível [...] (Comunicado interno do Hospital X).

Portanto, a análise desse período anterior à ruptura da crise no Hospital X possibilitou a identificação dos seguintes sinais de alerta: as epidemias anteriores de SARS e gripe aviária, os avisos de alerta realizados por 
uma profissional do hospital e os comunicados oficiais referentes ao início da pandemia de influenza A (H1N1).

A confirmação dos primeiros casos de influenza A (H1N1) no Brasil, em 7 de maio de 2009 (MINISTÉRIO DA SAÚDE, 2010), e na cidade de Curitiba, em 14 de junho de 2009 (SECRETARIA MUNICIPAL DA SAÚDE DE CURITIBA, 2009), foram considerados os primeiros sinais de vulnerabilidade, também característicos desse período anterior à ruptura da crise (KOVOOR-MISRA, CLAIR e BETTENHAUSEN, 2001; ROUX-DUFORT, 2007a; 2007b; 2009). Pode-se considerar que o sinal de vulnerabilidade mais intenso e amplamente reconhecido pela maioria dos funcionários foi a primeira internação de um paciente com diagnóstico de influenza A (H1N1) no Hospital X, em 22 de junho de 2009. Esse caso confirmou os sinais de alerta anteriores e o fato de que as pessoas já estavam vulneráveis à infecção pelo novo vírus.

No próximo tema, são apresentados alguns dados referentes ao processo de sensemaking realizado por profissionais do hospital em relação a esses sinais de alerta e vulnerabilidade.

Tema 2 (período A): "Tentar convencer as pessoas de que havia a possibilidade de uma pandemia, esse foi o problema"

Os relatos apresentados a seguir demonstram como alguns funcionários agiram diante dos sinais de alerta sobre a possível ocorrência de uma pandemia de influenza:

- Bom, no começo, foi tentar convencer as pessoas de que havia a possibilidade de uma pandemia, esse foi o problema [...].

- É, e isso foi visto até como uma postura de descrédito por algumas pessoas até chaves do processo, que achavam que isso era coisa da cabeça da [E 10] [...] (GF 1).

O pessoal até não acreditava muito, “será que vai mesmo chegar a alguma coisa?”, eu falei, gente foi dando o alerta; e tem muita gente que diz assim "ah, mas não deviam ter dado o alerta”, deviam, sim, fizeram muito bem, porque só assim a gente conseguiu se preparar, se organizar [...] (E 10).

Esses relatos demonstram como algumas pessoas agiram com descrédito diante dos sinais de alerta. Essa postura pode ser compreendida a partir das considerações de Turner (1976) em relação ao período de incubação da crise. Segundo o autor, "os eventos discrepantes começam a se acumular nesse período sem suscitar comentários, seja porque eles não são percebidos, seja porque seu significado é mal compreendido" (TURNER, 1976, p. 393, tradução nossa). Essa não percepção ou má compreensão dos sinais de alerta foi observada no caso estudado, sendo que, como descrito no relato do grupo focal 1, um dos problemas foi justamente convencer as pessoas de que os sinais de alerta indicavam uma efetiva possibilidade de ocorrência de uma pandemia. Como demonstrado no relato seguinte, essa interpretação dos sinais de alerta foi influenciada pela experiência anterior com a influenza aviária: "Como o surto anterior tinha sido da influenza aviária, não tinha sido uma coisa assim tão bombástica, como também já se comentava na época, então, as pessoas não acreditavam [...]" (E 1).

O fato de que na influenza aviária também houve alertas, que não se confirmaram, influenciou o modo como os profissionais realizaram os processos de sensemaking no início da pandemia de influenza A (H1N1). Pode-se observar, aqui, como o sensemaking é retrospectivo e baseado na plausibilidade (WEICK, 1995), ou seja, resgatando as experiências anteriores vivenciadas durante a gripe aviária, o sentido plausível construído por alguns funcionários foi de que os sinais de alerta eram apenas mais um alarme falso. 
Com base nas proposições de Weick (2005), pode-se considerar que esses funcionários realizaram uma normalização desses sinais de alerta, vindo a interpretar os sinais discrepantes como se fossem normais devido à semelhança com os sinais de experiências já conhecidas. É interessante destacar que, para Weick (2005), uma das situações propícias para a realização de normalizações é justamente diante de doenças emergentes. Segundo o autor, "a tentação de fazer isso deve ser especialmente forte quando a doença é 'emergente', pois, tomado literalmente, algo que emerge assemelha-se ao seu vizinho mais próximo em seu estágio inicial” (WEICK, 2005, p. 56, tradução nossa). Portanto, uma das implicações da normalização é que as pessoas podem deixar de prestar atenção nas novas informações que chegam sobre a situação vivenciada (WEICK, 2005), até mesmo quando se trata de sinais de alerta.

Além da normalização, pode-se observar outra conduta entre alguns profissionais do hospital, como observado no seguinte relato:

[...] como teve aquela situação da gripe aviária, né, e a [E 10] já é uma pessoa que sempre ela tá, o pessoal que trabalha com isso já tem essa visão, então, ela na gripe já tinha nos deixado dois (alertas), e não aconteceu nada, então, a gente, "não, a [E 10] tá exagerando", e ela não tava exagerando dessa vez [...], ela estava dizendo, e a gente achando "não, não, não vai ser tudo isso, não", de repente foi tudo isso assim, de uma hora pra outra, né [...], e ela tava dizendo "vai chegar, tá chegando, vai chegar, vai acontecer”, e a gente achando que não [...] (E 4).

A fala da Entrevistada 4 demonstra elementos que caracterizam uma reação de negação dos sinais de alerta (MITROFF, 2007; ROUX-DUFORT, 2007a) realizada por funcionários que não acreditavam que poderia haver uma pandemia, e muito menos que ela chegaria ao contexto do hospital. Esse relato é interessante à medida que destaca um elemento essencial do processo de sensemaking, o de que ele é guiado por crenças (WEICK, 1995). É possível perceber no relato diferentes crenças entre a Entrevistada 10 e a Entrevistada 4 em relação à possibilidade de ocorrência da pandemia, e, portanto, pode-se considerar que naquele primeiro momento as entrevistadas estavam construindo sentidos diferentes para uma mesma situação vivenciada por ambas (WEICK, 1995). As reações de negação dos sinais de alerta, justamente pela crença de que eles não passavam de mais uma simples ameaça, também podem ser observadas no relato de outros entrevistados:

[...] nós tivemos uma reunião com a [E 10], da Epidemiologia, quando ela expôs que a gripe já estava no Brasil, que tinham tido alguns casos e que nós deveríamos tomar algumas precauções [...], só que, até então, não tido nada aqui, nenhum caso aparente [...], não tinha nada, é, e assim, a gente achava que não, que isso não ia acontecer (E 2).

No início foi que ninguém queria acreditar, no começo foi assim, você falava e, "ah, mas isso não vai chegar aqui", "isso é pra quem vai pra fora”, "esse tipo de paciente não vem pro Hospital X” [...] (GF 2).

Por outro lado, observou-se que também houve funcionários do hospital que agiram de modo a reconhecer esses sinais de alerta, conforme demostrado a seguir:

Em 2009, o que aconteceu, quando saiu o alerta, no dia que saiu o alerta, a gente já iniciou o trabalho aqui no hospital [...], nesse mesmo dia de manhã eu já liguei pra Secretaria Estadual, pra Secretaria Municipal e aqui pro hospital pra gente ver como que a gente estaria se organizando para o início desse evento, né, desse novo evento, que ainda naquele início você não sabia direito o que era, o que ia acontecer (E 10).

A gente começou o treinamento foi em abril, quando a OMS já fez o alerta [...], e a gente já começou a ser organizar [...], ver de quanto material nós precisaríamos [...], treinar o pessoal pra usar as roupas, pra fazer os descartes, fazer todo o fluxo de atendimentos (E $5)$. 
Esses relatos exemplificam como alguns profissionais reagiram aos sinais de alerta de um modo diferente dos apresentados até então. Desde o primeiro alerta, emitido pela OMS no dia 24 de abril de 2009, essas pessoas já iniciaram ações de preparação do hospital para a possível pandemia. É interessante observar nos relatos como o sensemaking é um processo social realizado a partir de uma constante inter-relação entre ação e interpretação (WEICK, 1995; WEICK, SUTCLIFFE e OBSTFELD, 2005). Esses funcionários também buscaram construir sentidos para o que estava acontecendo a partir de ações que realizaram, tais como ligar para as secretarias municipal e estadual de saúde, buscar informações, organizar treinamentos para os funcionários do hospital etc.

Esses dados remetem à compreensão de que o modo como as pessoas realizam processos de sensemaking em uma situação de crise organizacional e as ações que praticam a partir desses sentidos construídos, influenciam o próprio desenvolvimento do processo de crise (WEICK, 1988; 1993; 2010). Assim, os sentidos que os funcionários foram construindo nesse período inicial podem ter contribuído tanto para o aumento da vulnerabilidade do hospital diante da ameaça de uma nova pandemia, especificamente nos casos em que houve normalização e negação dos sinais de alerta, quanto, por outro lado, para a redução da vulnerabilidade e dos impactos da crise, no caso dos funcionários que reconheceram os sinais de alerta e consideraram plausível a possibilidade de uma nova pandemia, realizando assim, ações voltadas à preparação do hospital.

No tema seguinte foram analisados os dados referentes ao momento de ruptura da crise, representado pelo período B na Figura 1.

Tema 3 (período B): "Foi numa sexta-feira, numa sexta-feira que eu nunca vou me esquecer [...], foi quando a Secretaria disse assim, 'vocês são referência e vão receber todos os casos graves'”

O momento de ruptura representa o início da crise e remete à ocorrência de um evento desencadeador (ROUX-DUFORT, 2007a; 2007b). A ruptura da crise no Hospital X está relacionada ao fato de que ele foi designado como hospital de referência para o atendimento das pessoas com influenza A (H1N1) de Curitiba e sua região metropolitana. Os relatos apresentados a seguir descrevem essa situação:

Foi numa sexta-feira, numa sexta-feira que eu nunca vou me esquecer, eu fiquei que nem louca aqui dentro, que foi quando a Secretaria disse assim, "vocês são referência e vão receber todos os casos graves" [...] (E 4).

O começo também foi aquele caos, né [...], como nós éramos referência, no dia seguinte que isso foi me informado, eu nunca vou me esquecer, foi no dia 24 de julho, no dia seguinte que avisaram que nós íamos ser referência encheu, porque aí todo mundo vinha pra cá [...] (E 3).

Tais descrições aproximam-se das considerações de Roux-Dufort (2007a; 2009), que caracteriza a ruptura da crise como um momento intenso em que prevalecem sentimentos de perda de controle. A intensidade do momento de ruptura pode ser observada quando os entrevistados afirmam que "nunca irão se esquecer daquele dia". O relato seguinte também descreve esse momento:

[...] tinha vindo um paciente e outro, mas na hora em que foi determinado que o Hospital X seria a referência pro atendimento dos pacientes mais graves da cidade inteira [...], a gente começou a receber ligação de tudo que é lugar, e foi aí que nós fechamos a porta do PA [Pronto Atendimento] [...], e nós tivemos que fechar realmente pra atender a gripe, então, foi uma mudança radical no nosso trabalho [...] (E 4). 
Esse relato indica que a designação do hospital como referência gerou mudanças no fluxo e nas jornadas de trabalho, em decorrência do aumento na demanda e da especificidade dos serviços prestados. Segundo Pearson e Clair (1998) e Roux-Dufort (2007a), no momento de ruptura da crise percebe-se a necessidade de que sejam tomadas decisões e praticadas ações em caráter de urgência. Roux-Dufort (2007a, p. 244, tradução nossa) ressalta que "a urgência de agir, ou melhor, a urgência de reagir à situação prevalece". A partir da designação do Hospital X como hospital de referência houve um aumento do fluxo de pacientes, o que gerou a necessidade de ações emergenciais, como, por exemplo, o deslocamento de pacientes graves que já estavam internados para liberar leitos para os pacientes que chegavam com sintomas de gripe. Como relata o Entrevistado 2, "em uma semana a coisa mudou, daí o hospital aqui ficou como referência, o Pronto Socorro, o PA, e a UTI atendiam só os pacientes da gripe, começaram a chegar vários casos [...]" (E 2).

Nesse caso, o fato de o Hospital X ser denominado hospital de referência, inclusive com a necessidade de fechamento do setor de Pronto Atendimento (PA) para o atendimento exclusivo a pacientes com influenza A (H1N1), foi compreendido como o evento desencadeador dessa crise organizacional. O fechamento do Pronto Atendimento do Hospital X foi um evento singular e extraordinário (ROUX-DUFORT, 2007b), que marcou uma interrupção no curso normal das experiências, impondo um antes e um depois (ROUXDUFORT, 2007b). Conforme os relatos já citados, houve uma mudança significativa no trabalho dos profissionais e no funcionamento do hospital após o fechamento do PA. Como afirmam Shrivastava, Mitroff, Miller et al. (1988, p. 288, tradução nossa), "esses eventos se tornam o ponto de referência para a identificação da crise". Nesse sentido, o fechamento do PA foi uma referência não apenas para os funcionários do Hospital $\mathrm{X}$, mas, também, para a comunidade externa, visto que o fato foi manchete dos principais jornais paranaenses publicados naquele período.

No tema seguinte são analisados os dados referentes à fase aguda da crise.

\section{Tema 4 (período C): “O que nós vivemos foi o caos”}

Neste tema foram analisados os dados referentes ao período de crise em si, ou seja, a fase aguda da crise (ROUX-DUFORT, 2007a).

Segundo Roux-Dufort (2007a, p. 245, tradução nossa), na fase aguda da crise "os gestores já não enfrentam mais uma mera perturbação, mas, sim, uma completa desestabilização do ambiente e da organização". Essa condição pode ser observada no seguinte relato:

O que nós vivemos foi o caos, nossa, pra mim eu acho que o que foi, foi o caos, o difícil foi o caos [...], essa é a palavra que fica, porque eu nunca vi aquilo, nunca tinha visto aquilo, aquele desespero, eи nunca vou me esquecer daquilo [...], porque pra mim foi o caos, isto aqui foi o caos (E 3).

O termo "caos" caracteriza a fase aguda da crise, representando o período de maior ambiguidade, incerteza e ameaça à organização. Esses aspectos podem ser observados na fala da Entrevistada 3:

Não se tinha uma dimensão, não sabia se ia ter 10,20, mas chegaram vários momentos em que nós tivemos os 14 leitos da UTI todos com H1N1, mais a Unidade de Emergência, a Infectologia nossa ficou toda com pacientes que talvez melhorassem, mas no começo nenhum melhorou, né, todos acabaram indo a óbito (E 3).

A incerteza foi uma característica marcante desse período, principalmente em relação ao desenvolvimento da epidemia, à proporção entre a quantidade de pacientes necessitando de internamento e a capacidade de atendimento do hospital, e quanto à possibilidade ou não de tratamento eficaz dos pacientes, já que no início muitos chegavam ao hospital em estado grave de saúde e não apresentavam melhora. Esses aspectos 
remetem ao conceito de crise organizacional proposto por Pearson e Clair (1998), no qual os autores destacam a questão da ambiguidade quanto a causas, efeitos e meios de resolução da crise.

Essa condição de incerteza e ambiguidade entre os funcionários do Hospital X já estava presente desde os primeiros sinais de alerta e vulnerabilidade, porém, intensificou-se após a ruptura da crise, permanecendo durante sua fase aguda. Os relatos a seguir exemplificam essa condição:

Nós não sabíamos o porte do que estava acontecendo, no começo era aquilo, ninguém sabia o que estava acontecendo [...], e a dúvida, a insegurança, né, porque você não sabe efetivamente com o que está lidando (E 6).

[...] a gente iria conseguir atender toda essa demanda? Até que tempo a gente conseguiria? (E 9).

[...] porque a gente estava desesperado para tentar entender o que estava acontecendo [...], porque, daí, a gente não sabia como o doente ia evoluir e todo mundo estava morrendo (E 11).

Esses relatos demonstram um aspecto importante sobre o sensemaking realizado no contexto de crise (WEICK, 1988; 2010), já que, segundo Weick (1995), é justamente diante de ocasiões de incerteza e ambiguidade que o processo de sensemaking é intensificado. Weick (1995) afirma que as pessoas se engajam em processo de sensemaking porque estão diante de uma situação para a qual não possuem nenhuma interpretação plausível, como pode ser observado nas falas acima. Diante dessa condição de incerteza vivenciada durante a crise, os funcionários do hospital buscavam compreender o que estava acontecendo, ou seja, construir sentidos plausíveis para aquelas situações que estavam vivenciando (WEICK, 1988; 1993; 2010; ROBERTS, MADSEN e DESAI, 2007; MAITLIS e SONENSHEIN, 2010).

Outra característica da fase aguda da crise refere-se ao seu alto impacto na organização, como demonstrado nos relatos seguintes:

[...] a maioria foi para a UTI, nós estávamos com 14 leitos, que a UTI nossa tem capacidade pra 14 leitos, nós estávamos com os 14 ativos no momento, é, nós tínhamos pacientes na Infectologia, na Maternidade [...] (E 7).

Isso era após 10 dias, a gente não estava nem no pico da gripe, a gente sabia que esse troço ia continuar piorando nos próximos dias e eu já estava com a UTI sobrecarregada, com o hospital já sobrecarregado (E 11).

Durante esse período da crise, um dos problemas mais críticos foi referente à grande quantidade de pacientes necessitando de atendimento versus a capacidade disponível para assistência. A fala dos entrevistados demonstra que houve uma sobrecarga na capacidade de atendimento do hospital, especialmente da UTI. Essa sobrecarga foi acentuada pela rapidez com que aumentou o número de casos graves. A velocidade com que as coisas ocorrem também é uma característica das situações de crise (LAGADEC, 2009). Nesse sentido, Fink (1986) ressalta que a dificuldade de gerenciamento de uma crise em sua fase aguda ocorre em função da "velocidade, como de uma avalanche, e a intensidade que geralmente acompanham e caracterizam essa fase" (FINK, 1986, p. 23, tradução nossa). Essa metáfora da avalanche ilustra bem a questão da rapidez associada ao grande impacto, elementos que podem ser observados no seguinte relato: "Desse momento catastrófico inicial até esse momento de 'puxa, estamos numa situação melhor' também dá em torno de uns 10 dias, só [...], é, então, tudo foi muito, muito rápido, muito rápido, tudo foi muito assim, nossa, tudo catastrófico [...]" (E 11).

Outra situação que caracteriza o impacto e a intensidade da crise remete aos óbitos de pessoas que contraíram a influenza A (H1N1). De certo modo, a ocorrência de óbitos é algo que faz parte da rotina de um 
hospital; porém, não com a intensidade e frequência com que ocorreram durante a crise, como demonstra o seguinte relato:

Teve dias em que eu chegava de manhã e via fila de carro de funerária lá fora, isso em 20 anos eu nunca vi aqui no hospital, tinham cinco carros de funerária esperando pra chegar porque tinham morrido cinco pacientes naquela noite, então, eram coisas assim, tristes [...] (E 5).

Estes óbitos relacionados à pandemia causaram um forte impacto nos profissionais do hospital, intensificado pela ocorrência de muitos casos entre pacientes jovens, como demonstram os seguintes relatos:

E eu sempre tenho a UTI lá em cima, é uma UTI de idosos, né, tem bastante idoso, e eu vi num momento assim, num dia desses de atendimento, que eu cheguei lá e a nossa média de atendimento era de pacientes de 20,24, 25 anos, e esse foi o lado triste [...], realmente uma UTI de jovens, jovens morrendo, isso foi o triste dessa pandemia [...], a gente via pessoas da equipe chorando por ver pessoas jovens morrendo (E 4).

[...] e agora o máximo foi que o pessoal da gripe teve uma mortalidade alta, então, eu tinha gente com o perfil da gripe né, que eram pessoas muito jovens, 20, 23 anos, que não tinham nenhuma doença até aquele momento [...], e daí, como é que morreu?Morrendo da gripe? (E 11).

Essas falas indicam como o falecimento de pacientes jovens foi considerado algo incongruente e atípico, afinal, não era normal que pessoas jovens, em boas condições de saúde, fossem a óbito em decorrência de uma gripe, assim como não era normal ter no hospital a maioria dos leitos da UTI com pacientes jovens. Essa situação demonstra como em uma crise ocorre um colapso do processo de sensemaking (WEICK, 1993). A nova realidade exposta abruptamente pela crise gera nas pessoas uma sensação de ausência de sentido, ou seja, por um momento, elas não conseguem construir sentidos plausíveis para aquilo que estão vivenciando (WEICK, 1993). Porém, por outro lado, essa ausência de sentido e a ocorrência de eventos incongruentes fazem com que as pessoas busquem se engajar em processos de construção de novos sentidos. Como afirmam Roberts, Madsen e Desai (2007, p. 108, tradução nossa), "as situações de crise forçam as organizações a construir rapidamente sentidos de ambientes turbulentos que geralmente não se assemelham a nada que eles já tenham vivenciado". Assim, justamente porque a crise provoca um questionamento das crenças e dos sentidos plausíveis compartilhados até então, as pessoas buscam se engajar em processos de sensemaking, principalmente por meio de circunstâncias que possibilitem a interação social e a comunicação (WEICK, 1995), tais como as reuniões do comitê de influenza A (H1N1) e os treinamentos realizados com os funcionários.

Os relatos anteriores demonstram, ainda, como o óbito desses pacientes jovens, bem como a crise como um todo, causou um impacto emocional nos profissionais do hospital (KOVOOR-MISRA, 1995; PEARSON e CLAIR, 1998; MAITLIS e SONENSHEIN, 2010), sendo identificada na fala dos entrevistados a menção aos sentimentos e sensações de tristeza, ansiedade, impotência, insegurança, medo e pânico. Os relatos seguintes ilustram esse impacto emocional:

É, na verdade, a pandemia, ela realmente mexeu com todo mundo, mexeu com o psicológico das pessoas, porque realmente é uma situação onde existem riscos pra população e pra própria população interna, né, pros trabalhadores, pra todo mundo que convive aqui no hospital [...], depois, nós todos estávamos, também, é com medo de todos pegarmos a doença e morrermos [...] (E 14).

O pânico que foi dentro do hospital com os próprios trabalhadores do hospital [...] (GF 2). 
No começo, o medo era uma coisa muito forte, a equipe médica, todos, todos, todos com muito medo das coisas, eh, não queriam atender os pacientes, né [...], a maioria das pessoas ficou apavorada, eles tinham medo de ter o paciente aqui [...] (E 3).

Como é possível observar, diversos funcionários do hospital, de diferentes setores e cargos, vivenciaram sensações de medo e pânico durante a crise, principalmente em relação ao risco de infectar-se com o novo vírus da gripe pandêmica. Como enfatizam Maitlis e Sonenshein (2010), é preciso levar em consideração a influência e o papel das emoções no processo de construção de sentidos. Nesse caso, pode-se observar que os sentimentos de medo e pânico contribuíram para que muitos funcionários construíssem um sentido plausível de que aquela situação era de extremo risco, e de que, em decorrência disso, não iriam realizar suas atividades nem mesmo ir ao hospital, o que eventualmente trouxe implicações quanto ao desempenho das atividades de funcionamento do hospital e de gerenciamento da crise.

Por fim, outro aspecto característico da fase aguda da crise verificado na pesquisa refere-se à ampla divulgação e cobertura da mídia (ROUX-DUFORT, 2007a), como observado no depoimento a seguir:

Teve o assédio da imprensa que foi infernal, eu fiquei com a minha cara estampada em tudo que é lugar, foi uma coisa horrorosa, gente, o tempo inteiro, eu acho que eu falei com todas as rádios de Curitiba e no jornal. [...]. Eles ficam procurando a tragédia, eles querem saber quantos doentes têm, quem morreu, quem não morreu, quantos foram, quantos têm internados [...] (E 3).

Esse relato demonstra como a crise organizacional assume proporções que vão além dos muros da organização em sua fase aguda (ROUX-DUFORT, 2007a), sendo amplamente divulgada pela mídia, o que também foi observado na análise documental de notícias publicadas em jornais.

Portanto, os dados analisados indicaram que a fase aguda do processo de crise organizacional ocorrido no Hospital X apresentou as seguintes características: (I) intenso estado de ambiguidade e incerteza entre os funcionários do hospital, principalmente em relação ao desenvolvimento da pandemia, à escolha do tratamento eficaz para os pacientes e à questão da demanda de internamentos e assistência; (II) o alto impacto da crise na organização, principalmente em relação ao rápido aumento do número de pacientes necessitando de atendimento, o que ocasionou uma sobrecarga da capacidade de assistência do hospital; (III) o forte impacto emocional da crise nos funcionários do hospital, decorrente, principalmente, dos óbitos causados pela influenza A (H1N1), considerando que a maior parte dos pacientes era constituída por jovens; (IV) a influência dos sentimentos de medo e pânico nos processos de sensemaking realizados pelos funcionários, principalmente em relação ao risco de infectar-se pelo vírus da nova gripe; e, por fim, (V) a ampla divulgação na mídia dos eventos relacionados à crise.

\section{Considerações Finais}

Este estudo teve por objetivo analisar o processo de crise organizacional ocorrido no Hospital X durante a pandemia de influenza A (H1N1) de 2009, considerando os processos de sensemaking realizados pelos funcionários do hospital ao longo da crise.

Uma das principais contribuições do estudo refere-se à realização de uma análise da crise organizacional a partir de uma abordagem processual (ROUX-DUFORT, 2007a; 2007b; 2009). Essa abordagem propiciou uma reflexão mais ampla sobre a crise ocorrida no Hospital $X$, uma vez que não se analisou apenas a fase aguda da crise, mas, também, as circunstâncias antecedentes que interferiam no processo de desenvolvimento da crise. Com base nessa abordagem, o processo de crise organizacional ocorrido no Hospital X foi analisado em três períodos. 
Primeiro, o período anterior à ruptura da crise, no qual foram analisados os sinais de alerta e de vulnerabilidade (FINK, 1986; KOVOOR-MISRA, 1995; ROUX-DUFORT, 2007a; 2007b; 2009). Foram considerados os seguintes sinais de alerta: duas epidemias anteriores, a SARS e a gripe aviária; os avisos dados por uma profissional do próprio hospital em 2008 sobre a possibilidade de ocorrência de novas epidemias de influenza; e, finalmente, os comunicados oficiais sobre a nova pandemia de influenza A (H1N1) emitidos pela OMS, pelo Ministério da Saúde, pela Secretaria Estadual de Saúde do Paraná, pela Secretaria Municipal de Saúde de Curitiba e pelo próprio Hospital X. Os primeiros casos de influenza A (H1N1) no Brasil e em Curitiba, bem como a primeira internação de um paciente com influenza A (H1N1) no Hospital X foram considerados sinais de vulnerabilidade.

No segundo período do processo de crise foi analisado o momento de ruptura, considerando a ocorrência do evento desencadeador da crise (TURNER, 1976; KOVOOR-MISRA, 1995; ROUX-DUFORT, 2007a; 2007b). A ruptura da crise está relacionada à caracterização do Hospital X como o hospital de referência para o atendimento dos pacientes com influenza A (H1N1) de Curitiba e sua região metropolitana. Nesse contexto, o fechamento do Pronto Atendimento do hospital para o atendimento exclusive a esses pacientes foi o evento central, já que explicitou aos funcionários do hospital e à comunidade externa o momento de ruptura da crise. Esse momento coincidiu com o período em que houve os maiores índices de infecção de pessoas pelo novo vírus e de realização de consultas e internações de pacientes de Curitiba e sua região metropolitana, segundo dados da Secretaria Municipal de Saúde de Curitiba (2009).

O terceiro período, o de fase aguda da crise, foi desencadeado imediatamente após o momento de ruptura (FINK, 1986; ROUX-DUFORT, 2007a; 2007b; 2009). Esse período foi caracterizado pelo forte impacto no funcionamento do Hospital X, principalmente em decorrência da grande demanda por assistência e internamentos de pessoas com influenza A (H1N1), verificando-se ser necessário implementar medidas como: a transferência de pacientes internados para outros hospitais, visando ao aumento da disponibilidade de leitos; o estabelecimento de novos fluxos e procedimentos de atendimento, principalmente nos setores de Urgência e Emergência, Pronto Atendimento e Unidade de Terapia Intensiva; a intensificação das práticas de controle de infecção hospitalar, treinamento de funcionários, dentre outras.

Esse período também foi marcado pela intensificação da condição de ambiguidade e incerteza em relação ao aumento da demanda por atendimento diante da limitação da capacidade de assistência do hospital, tendo em vista a gravidade dos casos e a dúvida quanto às possibilidades de proporcionar um tratamento eficaz aos pacientes.

Ainda em relação à fase aguda do processo de crise, pode-se observar a relevância de se considerar aspectos psicológicos relacionados à experiência dos funcionários na crise organizacional, seja em relação ao impacto emocional diante do óbito de pacientes com influenza A (H1N1), seja em relação às vivências de medo e pânico diante do risco de infecção pelo novo vírus.

O enfoque de aspectos psicológicos e sociais da crise organizacional se deu por meio da reflexão sobre os processos de sensemaking realizados pelos funcionários ao longo do processo de crise. Pode-se observar que a análise desses processos de sensemaking contribui para o entendimento do próprio processo de crise organizacional, principalmente em relação à atuação dos funcionários no contexto de crise.

Considerando o período anterior à ruptura da crise, foi possível compreender que o modo como os funcionários construíram sentidos sobre os sinais de alerta e de vulnerabilidade está relacionado ao modo como eles agiram nos primeiros momentos no processo de crise. Alguns funcionários desconsideraram esses sinais de alerta e vulnerabilidade, adotando condutas de normalização e/ou de negação. Por outro lado, houve pessoas que levaram em consideração esses sinais e construíram um sentido plausível de que havia a real possibilidade de ocorrência de uma pandemia de influenza, o que fez com que praticassem ações de preparação do hospital para essa situação.

A análise dos dados demonstrou, ainda, a influência e participação das emoções nos processos de sensemaking realizados pelos funcionários diante da crise (MAITLIS e SONENSHEIN, 2010), 
principalmente em relação às vivências de medo e pânico diante do risco de infecção, fazendo inclusive com que alguns funcionários deixassem de realizar suas atividades profissionais. Tais considerações também enfatizam a importância da compreensão dos processos de sensemaking nas situações de crise organizacional, tendo em vista a influência dos sentidos plausíveis construídos nas ações praticadas pelas pessoas durante a crise.

\section{Referências}

ALVES, J. E. P. Comunicação de risco, elemento-chave na gestão de crises corporativas e um desafio para o século XXI: a teoria na prática, situação atual e tendências. Organicom: Revista Brasileira de Comunicação Organizacional e Relações Públicas, ano 4, n. 6, p. 87-99, 2007.

BABBIE, E. The practice of social research. 8. ed. Belmont: Wadsworth, 1998.

BARDIN, L. Análise de conteúdo. Lisboa: Ed. 70, 2004.

BATISTA, L. L. A comunicação de riscos no mundo corporativo e o conteúdo da mensagem. Organicom: Revista Brasileira de Comunicação Organizacional e Relações Públicas, ano 4, n. 6, p. 101-113, 2007.

DENZIN, N. K.; LINCOLN, Y. S. Strategies of qualitative inquiry. Thousand Oaks: Sage, 1998.

FINK, S. Crisis management: planning for the inevitable. New York: AMACON, 1986.

FREITAS, H.; OLIVEIRA, M. Focus group: instrumentalizando o seu planejamento. In: GODOI, C. K.; BANDEIRADE-MELLO, R.; SILVA, A. B. Pesquisa qualitativa em estudos organizacionais: paradigmas, estratégias e métodos. São Paulo: Saraiva, 2006. p. 325-343.

GALINDO, F.; NOGUEIRA, H. G. P. O apagão aéreo no Brasil: o gerenciamento da crise e os efeitos sobre o relacionamento dos consumidores com as empresas aéreas. In: SEMINÁRIOS EM ADMINISTRAÇÃO, 2008, São Paulo. Anais... São Paulo: FEA-USP, 2008. p. 1-15.

GODOY, A. S. Introdução à pesquisa qualitativa e suas possibilidades. RAE: Revista de Administração de Empresas, v. 35, n. 2, p. 57-63, 1995.

Estudo de caso qualitativo. In: GODOI, C. K.; BANDEIRA-DE-MELLO, R.; SILVA, A. B. Pesquisa qualitativa em estudos organizacionais: paradigmas, estratégias e métodos. São Paulo: Saraiva, 2006. p. 115-143.

HUTCHINS, H. M.; WANG, G. Organizational crisis management and human resource development: a review of the literature and implications to HRD research and practice. Advances in Developing Human Resources, v. 10, n. 3, p. 310-330, 2008.

KOVOOR-MISRA, S. A multidimensional approach to crisis preparation for technical organizations: some critical factors. Technological Forecasting and Social Change, v. 48, p. 143-160, 1995.

.; CLAIR, J. A.; BETTENHAUSEN, K. L. Clarifying the attributes of organizational crises. Technological Forecasting and Social Change, v. 67, p. 77-91, 2001.

LAGADEC, P. A new cosmology of risks and crisis: time for a radical shift in paradigm and practice. Review of Policy Research, v. 26, n. 4, p. 473-485, 2009.

MAITLIS, S.; SONENSHEIN, S. Sensemaking in crisis and change: inspiration and insights from Weick (1988). Journal of Management Studies, v. 47, n. 3, p. 551-580, 2010.

MINISTÉRIO DA SAÚDE. Influenza pandêmica (H1N1) 2009: análise da situação epidemiológica e da resposta no ano de 2009. Boletim Eletrônico Epidemiológico, v. 10, n. 1, p. 1-21, 2010. 
MITROFF, I. I. The psychological effects of crises: deny denial-grieve before a crisis occurs. In: PEARSON, C. M.; ROUX-DUFORT, C.; CLAIR, J. A. (Ed.). International handbook of organizational crisis management. Thousand Oaks: Sage, 2007. p. 195-219.

OLIVEIRA, M. F. O papel essencial das Relações Públicas no gerenciamento de crises. Organicom: Revista Brasileira de Comunicação Organizacional e Relações Públicas, ano 4, n. 6, p. 161-173, 2007.

ORGANIZAÇÃO MUNDIAL DA SAÚDE - OMS. Global Alert and Responses: Influenza-like illness in the United States and México, 2009. Disponível em: 〈http://www.who.int/csr/don/2009_04_24/en/>. Acesso em: 28 out. 2010.

PAUCHANT, T. C.; DOUVILLE, R. Recent research in crisis management: a study of 24 authors' publications from 1986 to 1991. Organization Environment, v. 7, n. 1, p. 43-66, 1993.

PEARSON, C. M.; CLAIR, J. A. Reframing crises management. Academy of Management Review, v. 23, n. 1, p. 5976, 1998.

.; ROUX-DUFORT, C.; CLAIR, J. A. Introduction. In: (Ed.). International handbook of organizational crisis management. Thousand Oaks: Sage, 2007.

PERROW, C. Normal accidents: living with high-risk technologies. Princeton: Princeton University Press, 1999.

ROBERTS, K. H.; MADSEN, P.; DESAI, V. Organizational sensemaking during crisis. In: PEARSON, C. M.; ROUXDUFORT, C.; CLAIR, J. A. (Ed.). International handbook of organizational crisis management. Thousand Oaks: Sage, 2007. p. 107-122.

ROUX-DUFORT, C. A passion for imperfections: revisiting crisis management. In: PEARSON, C.; ROUX-DUFORT, C.; CLAIR, J. (Ed.). International handbook of organizational crisis management. Thousand Oaks: Sage, $2007 \mathrm{a}$. p. 221-252.

Is crises management (only) a management of exceptions? Journal of Contingencies and Crises Management, v. 15, n. 2, p. 106-114, $2007 \mathrm{~b}$.

The devil lies in details! How crisis build up within organizations. Journal of Contingencies and Crisis Management, v. 17, n. 1, p. 4-11, 2009.

SALINAS, A. V. Crises organizacionais são uma questão de ciclos? Notas críticas e reflexões sobre o campo da gestão de crises. In: ENCONTRO DA ANPAD, 25, 2001, Campinas. Anais... Florianópolis: ANPAD, 2001.

SANTANA, G. G. Administração de crises: questões teóricas e aplicabilidade na indústria turística. Turismo: Visão e Ação, v. 1, n. 1, p. 31-44, 1998.

Administração de crises: um novo paradigma. In: ENCONTRO DA ANPAD, 24, 2000, Florianópolis. Anais... Florianópolis: ANPAD, 2000.

SECRETARIA MUNICIPAL DA SAÚDE DE CURITIBA. Influenza pandêmica (H1N1) 2009 em Curitiba. Boletim Epidemiológico de Curitiba, ano 20, 2009. Edição especial.

SHRIVASTAVA, P. et al. Understanding industrial crises. Journal of Management Studies, v. 25, n. 4, p. 285-303, 1988.

STAKE, R. E. Qualitative case studies. In: DENZIN, N. K.; LINCOLN, Y. S. The Sage handbook of qualitative research. 3. ed. Thousand Oaks: Sage, 2005. p. 443-466.

THORSON, A.; EKDAHL, K. Avian influenza: is the world on the verge of a pandemic? ... and can it be stopped? Journal of Contingencies and Crisis Management, v. 13, n. 1, p. 21-28, 2005. 
TURNER, B. A. The organization and interorganization development of disasters. Administrative Science Quarterly, v. 21, p. 378-397, 1976.

WEICK, K. E. A psicologia social da organização. São Paulo: Edgar Blücher/Edusp, 1973.

Enacted sensemaking in crisis situation. Journal of Management Studies, v. 25, n. 4, p. 305-317, 1988.

The collapse of sensemaking in organizations: the Mann Gulch Disaster. Administrative Science Quarterly, v. 38, n. 4, p. 628-652, 1993.

. Sensemaking in organizations. Thousand Oaks: Sage, 1995.

. Making sense of the organization. Oxford: Blackwell, 2001.

. Managing the unexpected: complexity as distributed sensemaking. In: MCDANIEL JR., R. R.; DRIEBE, D. J. Uncertainty and surprise in complex systems. Heidelberg: Springer, 2005. p. 51-66.

Faith, evidence, and action: better guesses in an unknowable world. Organization Studies, v. 27, n. 11, p. 1723-1736, 2006. $\overline{537-550,} 2010$.

Reflections on enacted sensemaking in the Bhopal Disaster. Journal of Management Studies, v. 43, n. 3, p.

.; SUTCLIFFE, K. M.; OBSTFELD, D. Organizing and the process of sensemaking. Organization Science, v. 16, n. 4 , p. 409-421, 2005.

WU, D.; YANG, L.; WU, S. Crisis management of SARS in a hospital. Journal of Safety Research, v. 35, p. 345-349, 2004.

YIN, R. K. Estudo de caso: planejamento e métodos. Porto Alegre: Bookman, 2005. 